\title{
Urban Water Demand Estimates Under Increasing Block Rates
}

\author{
MICHAEL L. NIESWIADOMY \\ DAVID J. MOLINA
}

\begin{abstract}
A residential water demand equation is estimated using the only data set on water consumption that contains time series (monthly) observations on individual customers facing an increasing block rate schedule. Because the price of water both determines, and is determined by, usage, ordinary least squares estimation will yield biased estimates. Thus, two-stage least squares and instrumental variables techniques are used. The estimated coefficients on lawn size, weather, house size, and income have the expected signs and are statistically significant. However, there is not any significant response to changes in water price, perhaps due to the relatively low cost of water.
\end{abstract}

$\mathbf{I}$

NTEREST IN THE EFFICIENT USE of water resources has been growing throughout the United States. Economists have begun to focus particular attention on demand estimation. However, the opinions concerning the appropriate methodology for estimating water demand have varied significantly. Early water studies ignored the presence of block rates by simply using an ex post calculated average price (Gottlieb 1963, Young 1973, Foster and Beattie 1979). In his survey of studies of electricity demand, Taylor (1975) did not find a single study that was consistent with the classical theory of consumer behavior. Taylor suggested that the regressors should include marginal and average price. Subsequently, Nordin (1976) demonstrated that Taylor's specification was incorrect and should be modified to include a marginal price and a difference variable to account for the effects of intramarginal rates and fixed fees. Difference is defined as the total bill minus what the bill would have been if all units had been purchased at the marginal price.

Both Michael L. Nieswiadomy and David J. Molina are assistant professors of economics at North Texas State University. 
Recently, some researchers have employed Nordin's theoretical model with limited success (Billings and Agthe 1980, Howe 1982, Jones and Morris 1984). However, others have claimed that the measure(s) of price to which consumers respond is an empirical question (Foster and Beattie 1981, Opaluch 1982, Chicoine and Ramamurthy 1986). These researchers have attempted to test the use of marginal price (and sometimes the difference variable) versus average price, with mixed results. One problem which must be addressed by all researchers is simultaneity. Since the price of water both determines, and is determined by, consumption (under a block pricing scheme), OLS estimation of any of the above models may lead to biased and inconsistent estimates. Several authors have used instrumental variables (IV) techniques to address this problem in electricity demand (Wilder and Willenborg 1975; McFadden, Puig, and Kirschner 1977; and Henson 1984) and in water demand estimation (Jones and Morris 1984; Deller, Chicoine, and Ramamurthy 1986; and Agthe, Billings, Dobra, and Raffiee 1986). This paper will compare the IV, two-stage least squares (2SLS) and OLS methods in estimating water demand using a unique data set.

The data set employed in this analysis is unique because it is the only microeconomic data set on water consumption that contains time series (monthly) observations on individual customers facing an increasing block schedule. (Some water utilities have begun using increasing rather than decreasing block schedules.) We know of only four other micro data sets on water consumption: Danielson 1979; Hanke and de Mare 1982; Jones and Morris 1984; Deller, Chicoine and Ramamurthy 1986; and Chicoine, Deller, and Ramamurthy 1986. However, these studies use decreasing block data. We feel that more research is needed using micro water data sets. To this point, Schefter and David (1985) have demonstrated the problems involved in using aggregate rather than micro data. They hypothesize that some of the controversy in the water demand estimation literature is directly attributable to the use of aggregate data. Furthermore, as Houthakker and Taylor (1970) have noted, the use of cross-section data requires making the "heroic" assumption that the spatial effect of the explanatory variable be the same as the temporal effect.

This paper proceeds as follows. In the second section the data set is presented. The third section describes the model and estimation techniques. The fourth section examines the results and draws inferences. The fifth section summarizes the findings.

\section{The Data Set}

It is unfortunate that many empirical studies expound upon the methodology but only briefly describe the data set. It is to be hoped that Dewald, Thursby, and Anderson's 1986 replication study will encourage more careful attention to details, particularly in the data set. With these remarks in mind, the description of the data set follows.

This study uses the only cross-section time series data set on individual customers' water use under increasing block rates. It consists of a random 
sample of 104 individual customers' monthly water use records from the city of Denton, Texas (population 60,000) for the summer months of 1981-85. The sample was screened to include only residences with lawns (the irrigable area). (The same families occupied these homes over the entire time period.) The following information was obtained from the microfiche billing records of the city's water department: (1) cycle number, (2) read date, (3) days in billing period, (4) water use (in gallons), and (5) total water bill (in dollars). Consumption data for each billing cycle were converted to a thirty-day period for consistency.

The sample was cross-referenced with records at the Denton County Appraisal District to determine house size, lot size, house age and assessed home values. House size and lot size were used to determine irrigable area (termed "lawn size"). Customers with swimming pools were deleted because it is believed that their behavior should be modelled differently.

Since time series data were used, an income proxy was needed. The 1984 assessed value was used as a base income proxy. Since banks do not generally allow a mortgage payment to be more than one-third of monthly income, monthly income can be roughly approximated (as a lower bound) as (assuming a 10 percent interest rate):

\section{Monthly Income $=$ Assessed Value $\times 0.10 \times 3 / 12$.}

This monthly income measure was adjusted on a monthly basis using the change in average earnings of manufacturing workers in the Dallas-Fort Worth Metropolitan Area, which includes Denton (U.S. Department of Labor 1985). The change in nonwage compensation for workers in the U.S. (Statistical Abstract of the U.S., 1986, p. 417) was also added to these figures. The annual rates of change were converted to monthly rates. All dollar figures were divided by the monthly CPI $(1967=100)$.

Since this study utilizes monthly consumption data, a comprehensive weather variable $(W)$ is particularly important. W was calculated as potential evapotranspiration (PEVT) for bermuda grass minus precipitation. The details of the calculation are available upon request.

Some summary statistics of the data set are given in Tables 1 and 2. In Table 1 the rate schedule is described. Notice that the rate schedule changed every year during the five-year period. In real terms, the price increased 33 percent in the second block and 25 percent in the first block over the entire five-year period. It is also interesting to note that most studies of water (and electricity) have used decreasing block data. This is the only study to our knowledge that examines individual water customers' reactions to price changes under an increasing block schedule. Most of the data in Table 2 require no explanation. However, it should be noted that the percentage of income spent on water is probably smaller than l percent since the income proxy probably underestimates household income, as discussed above. 
TABLE 1. INCREASING BLOCK RATE SCHEDULE (NUMBER OF OBSERVATIONS: 2702)

\section{Block}

(in thousands Mean Marginal

of gallons Monthly Price Per Real Price Number of

Period Per month) Consumption 1000 gal. (1967\$) Observations

\begin{tabular}{ccrrrr}
\hline 1 & $0-20$ & 9.73 & $\$ 1.00$ & $\$ 0.36$ & 371 \\
$(6 / 81-9 / 81)$ & $20-$ over & 29.60 & 1.15 & 0.42 & 78 \\
2 & & & & & \\
$(6 / 82-9 / 82)$ & $20-20$ & 8.88 & $\$ 1.10$ & $\$ 0.38$ & 373 \\
3 & $0-$ over & 29.16 & 1.30 & 0.45 & 82 \\
$(6 / 83-9 / 83)$ & $20-$ over & 32.29 & 1.42 & 0.47 & 108 \\
4 & $0-20$ & 10.80 & $\$ 1.30$ & $\$ 0.42$ & 527 \\
$(5 / 84-10 / 84)$ & $20-$ over & 32.29 & 1.60 & 0.52 & 144 \\
5 & & & & & \\
$(5 / 85-10 / 85)$ & $20-$ over & 33.98 & 1.80 & 0.56 & 110 \\
\hline
\end{tabular}

Note: The monthly CPI for the first month of each period is used for deflating.

TABLE 2. SUMMARY STATISTICS (NUMBER OF OBSERVATIONS: 2702)

\begin{tabular}{lcc}
\hline & Mean & Standard Deviation \\
\hline Monthly Consumption (1000 gal.) & 14.12 & 11.09 \\
Price (1967\$/1000 gal.) & 0.42 & 0.05 \\
Monthly Bill (1967\$) & 7.28 & 5.36 \\
Bill as Percent of Income & $1.10 \%$ & $0.9 \%$ \\
Value of Residence (1967\$) & $14,684.35$ & $6,035.55$ \\
Monthly Income (1967\$) & 729.08 & 300.16 \\
Difference Variable (1967\$) & 1.63 & 0.87 \\
Age (years) & 26.98 & 12.97 \\
Lawn Size (square feet) & $8,914.74$ & $3,227.92$ \\
Weather* & 0.46 & 0.14 \\
Temperature* (Fahrenheit) & 79.99 & 6.07 \\
Rain* (inches) & 0.11 & 0.10 \\
\hline
\end{tabular}

${ }^{*}$ Mean daily measurements. 


\section{The Model and Demand Estimating Techniques}

The model chosen for this study is a variation of the form of the demand function suggested by Nordin (1976). It incorporates the rate schedule explicitly in the demand equation. The difference variable, which accounts for intramarginal effects, should have a coefficient equal in magnitude and opposite in sign of the income coefficient. Lawn size, income, house age and the weather variable are included as additional explanatory variables. The model is specified as follows. (An implicit time subscript is assumed.)

$$
\mathrm{Q}_{\mathrm{i}}=\mathrm{X}_{\mathrm{i}} \alpha+\beta_{1} \mathrm{c}_{1}+\beta_{2} \mathrm{M}_{\mathrm{i}}+\beta_{3} \mathrm{D}_{\mathrm{i}}+\mathrm{u}_{\mathrm{i}}
$$

where

$$
\begin{aligned}
& Q_{i}=\text { observed monthly water consumption (gallons) of } \\
& \text { the } i^{\text {th }} \text { household } \\
& c_{i}=\sum_{j=1}^{J_{1}} d_{j i} c_{j 1} \\
& D_{i}=\sum_{j=1}^{J_{i}} d_{j i} D_{j 1} \\
& \mathrm{~d}_{\mathrm{j} \mathrm{t}}=1 \text { if the } \mathrm{i}^{\text {th }} \text { household consumes in the } \mathrm{j}^{\text {th }} \text { block } \\
& =0 \text { otherwise } \\
& D_{j i}=\sum_{k=2}^{j} q_{k-1}\left(c_{k-1, i}-c_{k i}\right)-\text { Flat } \\
& =\text { Monthly difference variable } \\
& M_{1}=\text { Monthly income } \\
& \mathrm{J}_{\mathrm{i}}=\text { Number of blocks in the } i^{\text {th }} \text { household's rate } \\
& \text { schedule } \\
& q_{j}=\text { is the upper endpoint of block } j \\
& c_{j}=\text { the marginal price in block } \mathrm{j} \text { for the } \mathrm{i}^{\text {th }} \text { household } \\
& \text { Flat }=\text { Flat rate charge } \\
& \mathrm{X}_{1}=\text { explanatory variables (constant, lawn size, } \\
& \text { weather, house age) } \\
& \left\langle\alpha \beta_{1} \beta_{2} \beta_{3}\right\rangle=\text { vector of parameters to be estimated and, } \\
& u \sim N\left(0, \sigma^{2}\right) .
\end{aligned}
$$


It is generally accepted that OLS estimates of water demand functions for consumers facing block rate schedules yield biased estimates of price elasticity (for example, see Terza 1986), since the price variable is correlated with the random error term. As described by Henson (1984), the coefficient on marginal price is expected to be biased toward zero and the coefficient on difference to be biased away from zero, under an increasing block structure. A Hausman (1978) specification test was used to test for this possible simultaneity bias. The Hausman test utilizes the result that the OLS estimator is consistent and asymptotically efficient under the null hypothesis that the price variables are exogenous, but is inconsistent under the alternative hypothesis. The instrumental variable estimators, $b_{i v}$, are consistent under both the null and alternative hypotheses, but not asymptotically efficient under the null hypothesis. The test statistic is

$$
\mathbf{m}=\mathbf{b}^{\prime}\left(\mathrm{V}_{\mathrm{iv}}-\mathrm{V}_{\mathrm{ols}}\right)^{-1} \mathbf{b},
$$

where $b=b_{i v}-b_{o l s}$, and $V_{i v}$ and $V_{o l s}$ are variance - covariance estimates under instrumental variable and OLS techniques, respectively. This statistic has an asymptotic chi-square distribution with degrees of freedom equal to the number of explanatory variables. The calculated Hausman's test statistic is 887 , which greatly exceeds the critical value of $\mathrm{x}^{2}$ at the 1 percent level of significance of 18.475 with seven degrees of freedom. OLS estimates are presented in this study for purposes of comparison.

While several instrumental variables techniques have been suggested, we focus on two commonly used ones. The first technique introduces a separate price equation in a Two-Stage Least Squares (2SLS) procedure introduced by Wilder and Willenborg (1975). Price is regressed against lawn size, weather, income, age and the two marginal prices. The predicted price is used in the second stage as a regressor. Another approach was suggested by $\mathrm{McF}$ adden, Puig, and Kirschner (1977). McFadden et al. regress actual household consumption on a set of variables which represent the typical bill. However, they did not have access to the actual rate schedules for their data. This caused two problems, as Terza notes:

\footnotetext{
They were not able to regress observed electricity consumption on the actual rate schedule. Instead, they were forced to approximate the rate schedule by typical electric bills at various levels of consumption. In the second stage, they were unable to use the actual rate schedule to compute the values of the price instrument (Terza 1986, p. 1137).
}

We employ an application of the IV method as used by Terza, which is not subject to these problems. In the first stage, observed water demand was regressed on actual marginal prices that the household would face at two different levels of water demand (10 and 20 thousand gallons and the exogenous variables). In the second stage, the actual rate schedule was used to obtain predicted marginal prices. The difference variable is calculated using these predicted marginal prices. Both of these adjustments to the IV method are likely to improve the reliability of the estimates (Terza 1986). 


\section{Interpretation of Results}

The results presented in Table 3 are of interest on four accounts. First, the bias in the water demand price coefficent is obvious when OLS produces a positive price coefficient. It is most apparent in this study which uses increasing block data, whereas all other water demand studies, using micro data, have used decreasing block data. This is a particularly interesting result, since some researchers have found that "Instrumental estimation of price produces results not fundamentally different from simpler OLS approaches" (Jones and Morris 1984, p. 201). Furthermore, these results are of practical significance since some water utilities have begun using increasing rather than decreasing block rate schedules. Second, in all three models our explanatory variables (i.e., lawn size, weather, house age, and income) were always significant and had the expected signs. The age coefficient is expected to be negative for several reasons. Newer homes are more likely to have more water-using devices, such as dishwashers, showers, hot tubs, etc. Older homes generally have trees which provide more shade for the grass. The reduced evaporation from the grass may more than offset the additional water used by the trees.

TABLE 3. WATER DEMAND ESTIMATES

\begin{tabular}{lccc}
\hline Variable & OLS & IV & 2SLS \\
\hline Constant & -14.33 & -2.32 & -1.03 \\
& $(-9.06)^{*}$ & $(-0.72)$ & $(-0.43)$ \\
Lawn Size & 0.000306 & 0.00065 & 0.0007 \\
& $(5.62)^{*}$ & $(8.59)^{*}$ & $(7.13)^{*}$ \\
Weather & 8.89 & 19.82 & 18.97 \\
& $(8.60)^{*}$ & $(12.15)^{*}$ & $(9.43)^{*}$ \\
Price & 24.89 & 6.64 & -0.09 \\
& $(6.09)^{*}$ & $(0.49)$ & $(-0.01)$ \\
Income & 0.0059 & 0.0039 & 0.0026 \\
& $(0.97)$ & $(4.71)^{*}$ & $(2.90)^{*}$ \\
Difference & 6.94 & -2.12 & -0.29 \\
& $(31.25)^{*}$ & $(-0.73)$ & $(-0.21)$ \\
Age & -0.028 & -0.05 & -0.05 \\
& $(-1.99)^{*}$ & $(-3.11)^{*}$ & $(-2.52)^{*}$ \\
$\mathrm{R}^{2}$ (adjusted) & 0.54 & 0.12 & 0.12 \\
Income-Elasticity & 0.305 & $0.20^{*}$ & $0.13^{*}$ \\
\hline
\end{tabular}

Note: t-ratios in parentheses.

*Significant at 0.01 level. 
A third point of interest is the insignificant coefficient of the difference variable. The comparison with the income variable is not too interesting in this particular case, even though the null hypothesis of "equal and opposite in sign" cannot be rejected. This result is probably a reflection of the overall lack of consumer response to prices and difference (which is a trivial fraction of income). This result seems to be consistent with the failure of other studies to empirically verify the Nordin theoretical model. If the difference variable had been significant, it appears to have a 100 to 1000 times larger coefficient, a result found in some other studies.

A fourth point of interest is that once the endogeneity in the price variable had been purged via 2SLS or IV, the price coefficient became statistically insignificantly different from zero. This result, quite different from results from previous studies, may perhaps be attributable to four reasons. First, since the average monthly water bill amounts to no more than one percent of the monthly income (see Section Two) it is possible that the consumer does not react to price changes. In a survey of Texas residential water users, Murdoch, Hamm, and Albrecht (1986) found that only 44 percent of those customers surveyed could recall or find a recent water bill. Our study may be the first to notice this phenomenon because other studies (except Chicoine, Deller, and Ramamurthy 1986) have not used microeconomic time series data. As Houthakker and Taylor (1970) note, the use of micro time series data is preferable because the use of cross-section data requires that the spatial effect of explanatory variables be the same as the temporal effect. Thus they conclude that using cross-section data to obtain information on how individuals respond to such changes requires "heroic" assumptions.

Second, we note that there may be a problem with the finding of downward sloping demand curves in some studies. These findings may be attributable to the fact that consumers were decreasing their water consumption not because of an increase in price, but instead, as a civic response to water authorities' exhortation to conserve water. As an example, Billings and Agthe's (1980) study covered a period of Tucson, Arizona (1976-77) when a strong advertising campaign was conducted simultaneously with a rate increase. In fact, a few years later, per capita consumption rose to pre-1976 levels (see Martin et al. 1984).

A third reason for the discrepancy between these results and those of previous studies may arise because this is the first study to estimate water demand using micro data from increasing rather than decreasing block structures. It is possible that studies which used decreasing block data found decreasing demand functions because those consumers who wished to consume more water (regardless of price, as long as this remained an insignificant portion of their income) were, by the nature of the rate schedule, paying less per unit. In other words, it may be possible that some of the simultaneity effects of the decreasing rate schedule may still be biasing the estimated price coefficient away from zero. It would be useful to see more research done on increasing block data. 
One more reason which may explain the insignificant price coefficient is that during the study period the water rates changed every year. Under these circumstances it is possible that the consumer did not have sufficient time to react to the new prices before they were changed again. In order to test this hypothesis, we introduced a partial adjustment model (Kmenta 1986, pp. 529-30). In this model, the consumer faces a linear demand function like that presented in Equation 1. However, it is assumed that the consumer does not adjust instantaneously to a price change, but instead adjusts actual consumption, $Q$, from desired consumption, $\widetilde{Q}$, in the form presented in Equation 2:

(2) $Q_{i, v}-Q_{i, v-1}=\lambda\left(\widetilde{Q}_{i, v}-Q_{i, v-1}\right)$

where $i$ is the $i^{\text {th }}$ consumer and $v$ represents the current year. The motivation for this model can be expressed as the consumer's desire to minimize two opposite costs, the cost of being in disequilibrium and the cost of changing the existing capital stock, habits, etc. It can be easily shown that the solution to this partial adjustment model for Equation 1 is:

(3) $\mathrm{Q}_{1}=\mathrm{X}_{\mathrm{i}} \alpha^{*}+\beta_{1}^{*} \mathrm{c}_{\mathrm{i}}+\beta_{2}^{*} \mathrm{M}_{\mathrm{i}}+\gamma \mathrm{Q}_{\mathrm{i}, \mathrm{v}-1}+\mathrm{u}_{\mathrm{i}}^{*}$

where $0<\gamma<1, \gamma=1-\lambda, \alpha^{*}=\lambda \alpha, \beta_{1}^{*}=\lambda \beta_{1}, \beta_{2}^{*}=\lambda \beta_{2}, u_{i}^{*}=\lambda u_{1}$. Note that $\beta_{1}^{*}$ is a measure of the slope of the short-run demand curve, while $\beta_{\mathrm{i}}$ is a measure of the slope of the long-run demand curve.

The results for this dynamic model are presented for all estimating techniques in Table 4. The OLS estimates continued to present an upward sloping demand curve, though the magnitude of the slope decreased. The IV and the 2SLS, on the other hand, exhibited statistically insignificant coefficients. The long-run slope is also statistically insignificant. The IV model provides results not markedly different from the 2SLS results.

Even using a partial adjustment model, we are unable to find convincingly downward sloping water demand functions using our microeconomic panel data with increasing block rates. This suggests, once more, that water consumption may not be very sensitive to price as long as the water bill remains such a small portion of the consumer's income.

\section{Conclusions}

This paper represents the first estimation of water demand using microeconomic panel data for urban consumers facing increasing block rates. In addition, it is the first work to use a weather variable which includes evapotranspiration matched to the billing cycle of each consumer.

Three different techniques were applied to the data under two different scenarios. In the static scenario, the OLS technique resulted in a statistically positive price effect whereas the 2SLS and IV techniques resulted in insignificant price effects. Four different explanations for this apparent anomaly were given. The first three are based primarily on the nature of the data and the fact that the monthly water bill remains less than 1 percent of the consumer's income. 
The fourth possible explanation is based on the possibility that the customer did not rapidly adjust to the price changes. This hypothesis was tested by using a partial adjustment model scenario, but the price coefficient remained statistically insignificant.

Both scenarios showed similar results for the lawn size, weather, house age and income variables, all of which yielded the expected signs and were statistically significant. Furthermore, the IV results do not appear to differ much from the 2SLS results.

These results suggest that the determination of the price elasticity of demand for water will remain difficult, as long as the water bill remains an insignificant portion of the customer's budget. More analysis is needed using other microeconomic data sets.

TABLE 4. WATER DEMAND FOR DYNAMIC MODEL

\begin{tabular}{lccc}
\hline Variable & OLS & IV & $2 S L S$ \\
\hline Constant & -12.28 & -0.998 & 0.43 \\
& $(-7.51)^{*}$ & $(-0.29)$ & $(0.17)$ \\
Lawn Size & 0.00021 & 0.00038 & 0.00048 \\
Weather & $(3.86)^{*}$ & $(4.85)^{*}$ & $(5.45)^{*}$ \\
& 7.84 & 15.62 & 15.58 \\
Lag Consumption & $(7.45)^{*}$ & $(9.07)^{*}$ & $(8.35)^{*}$ \\
& 0.20 & 0.441 & 0.44 \\
Price & $(13.05)^{*}$ & $(20.65)^{*}$ & $(10.23)^{*}$ \\
& 18.22 & 6.39 & -4.95 \\
Income & $(4.39)^{*}$ & $(0.47)$ & $(-0.76)$ \\
& 0.00025 & 0.00187 & 0.0013 \\
Difference & $(0.41)$ & $(2.17)^{*}$ & $(1.46)$ \\
& 6.58 & -3.88 & -1.16 \\
Age & $(28.32)^{*}$ & $(-1.33)$ & $(-0.80)$ \\
& -0.022 & -0.032 & -0.037 \\
R ${ }^{2}$ (adjusted) & $(-1.56)$ & $(-1.87)$ & $(-1.87)$ \\
Income-Elasticity & 0.57 & 0.29 & 0.24 \\
Long-Run Slope & 0.013 & $0.096^{*}$ & 0.067 \\
& & 11.41 & -8.83 \\
& & $(0.47) \dagger$ & $(-0.75) \dagger$ \\
\hline
\end{tabular}

Note: t-ratios in parentheses.

*Significant at 0.01 level.

$\dagger$ The asymptotic variance is calculated as:

$\operatorname{Var}(\Psi)=(1 / 1-\gamma)^{2} \operatorname{Var} \beta_{1}^{*}+\left[\left(\beta_{1}^{*} /(1-\gamma)^{2}\right]^{2} \operatorname{Var} \gamma+2(1 / 1-\gamma)\right.$ $\left[\left(\beta_{1}^{*} /(1-\gamma)^{2}\right] \operatorname{Cov}\left(\beta_{1}^{*}, \gamma\right)\right.$

where $\Psi=\beta_{\mathrm{I}}^{*} /(1-\gamma)$. 


\section{R E F E R E N E S}

Agthe, Donald E., Bruce R. Billings, John L. Dobra, and Kambizz Raffiee. 1986. A simultaneous equation model for block rates. Water Resources' Research January 1-4.

Billings, R. Bruce, and Donald E. Agthe. 1980. Price elasticities for water: A case of increasing block rates. Land Economics February 73-84.

Chicoine, David L., and Ganapathi Ramamurthy. 1986. Evidence on the specification of price in the study of domestic water demand. Land Economics February 26-32.

Chicoine, David L., Steven C. Deller, and Ganapathi Ramamurthy. 1986. Water demand estimation under block rate pricing: A simultaneous equation approach. Water Resources Research June 859-63.

Danielson, Leon E. 1979. An analysis of residential demand for water using micro time-series data. Water Resources Research August 763-67.

Deller, Steven C., David L. Chicoine, and Ganapthi Ramamurthy. 1986. Instrumental variables approach to rural water service demand. Southern Economic Journal October 333-46.

Dewald, W. G., J. G. Thursby, and R. G. Anderson. 1986. Replication in empirical economics: The Journal of Money, Credit and Banking project. The American Economic Review September 587-603.

F oster, Henry S., Jr., and Bruce Beattie. 1979. Urban residential demand for water in the United States. Land Economics February 43-58.

1981. Urban residential demand for water in the United States: Reply. Land Economics May 257-65.

Gottlieb, M. 1963. Urban domestic demand for water: A Kansas case study. Land Economics May 204-10.

Griffiths, John F., et al. 1980. Agroclimatic atlas of Texas, part 3: The mean distribution and variation of solar radiation and sunshine in Texas. College Station: The Texas Agricultural Experiment Station, Texas A\&M University. December.

Hanke, Steve, and Lennart de Mare. 1982. Residential water demand: A pooled, time series, cross section study of Malmo, Sweden. Water Resources Bulletin August 621-25.

Hausman, J. A. 1978. Specification tests in econometrics. Econometrica November $1251-271$.

Henson, Steven. 1984. Electricity demand estimates under increasing block rates. Southern Economic Journal July 147-56.

Houthakker, H.S., and L. D. Taylor. 1970. Consumer Demand in the United States: Analysis and Projections. Cambridge: Harvard University Press.

Howe, Charles W. 1982. Impact of price on residential water demand: Some new insights. Water Resources Research August 713-16.

Kmenta, J. 1986. Elements of econometrics. New York: MacMillan Publishing Co.

Jones, C. Vaughan, and John R. Morris. 1984. Instrumental price estimates and residential water demand. Water Resources Research February 197-202.

Martin, William E., et al. 1984. Saving water in a desert city. Washington, DC: Resources for the Future.

McFadden, Daniel, C. Puig, and D. Kirschner. 1977. Determinants of the longrun demand for electricity. Proceedings of the American Statistical Association, business and economic section, Part I. August 109-13. 
Murdoch, Steve H., Rita R. Hamm, and Don E. Albrecht. 1986. Demographic and social factors affecting water use in urban areas in Texas. Working Paper, Department of Rural Sociology, Texas A\&M University. Presented at the 21st Water for Texas Conference on "Urban water resources management," October 2-3, College Station, TX.

Nordin, John A. 1976. A proposed modification on Taylor's demand analysis: Comment. The Bell Journal of Economics Autumn 719-21.

Opaluch, James J. 1982. Urban residential demand for water in the United States: Further discussion. Land Economics May 224-27.

Schefter, J. E., and E. L. David. 1985. Estimating residential water demand under multi-part tariffs using aggregate data. Land Economics August 272-80.

Smithsonian Institution. 1951. Smithsonian meteorological tables, sixth revised edition. Washington, DC.

Taylor, L. D. 1975. The demand for electricity: A survey. The Bell Journal of Economics. Spring 74-110.

Terza, Joseph V. 1986. Determinants of household electricity demand: A two-stage probit approach. Southern Economic Journal April 1131-139.

U.S. Department of Commerce. Statistical abstract of the United States, 1986.

U.S. Department of Labor, Bureau of Labor Statistics. 1985. Dallas-Fort Worth, Texas area wage survey. Bulletin 3025-71.

U.S. Weather Bureau. 1981-85. Climatological data, Texas. Asheville, NC: National Oceanic and Atmospheric Administration.

1981-85. Local climatological data monthly summary, Texas. Asheville, NC: National Oceanic and Atmospheric Administration.

van Bavel, Cornelius H. M., unpublished notes, Department of Soil and Crop Sciences, Texas A\&M University, College Station, TX, 1986.

Wilder, Ronald P., and John R. Willenborg. 1975. Residential demand for electricity: A consumer panel approach. Southern Economic Journal October 212-17.

Young, R. A. 1973. Price elasticity of demand for municipal water: Case study of Tucson, Arizona. Water Resources Research December 1068-072. 
Copyright of Growth \& Change is the property of Wiley-Blackwell and its content may not be copied or emailed to multiple sites or posted to a listserv without the copyright holder's express written permission. However, users may print, download, or email articles for individual use. 